\title{
Synthesis and Molecular Properties of Partially Fluorinated DNTTs
}

\author{
Matthias W. Tripp, ${ }^{[a]}$ Daniel Bischof, ${ }^{[b]}$ Maximilian Dreher ${ }^{[b]}$ Gregor Witte, ${ }^{*[b]}$ and Ulrich Koert ${ }^{*[a]}$
}

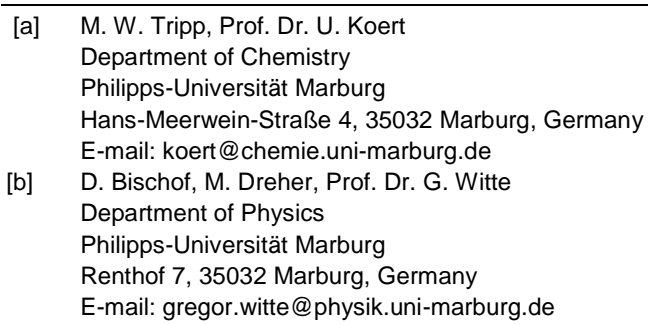

Supporting information for this article is given via a link at the end of the document.

\begin{abstract}
Tetrafluoro-dinaphtothienothiophene $\left(\mathrm{F}_{4} \mathrm{DNTT}\right)$ and 1,2,3,4,8,9,10,11-octafluoro-dinaphtothienothiophene ( $F_{8}$ DNTT) were synthesized via bisthiomethyl alkene intermediates which were accessible by McMurry coupling or Wittig olefination of partially fluorinated naphthalene precursors. DFT-based electronic structure calculations, X-ray absorption spectroscopy (NEXFAS) and UV/Vis measurements were used for HOMO/LUMO gap determination and to analyse the electronic structures of the partially fluorinated DNTTs. Reduced exciton binding was observed in thin films.
\end{abstract}

\section{Introduction}

The promising potential of using $\pi$-conjugated molecules or polymers as active semiconducting material for flexible organic electronics applications such as e.g. rollable displays, costeffective sensors or electronic skin has triggered the synthesis of new organic materials suited for such applications. ${ }^{[1]}$ Among the organic semiconductors, pentacene 1 (Figure 1) has long been considered a model system, as it forms well-ordered crystalline films with reasonably high charge carrier mobility that were commonly used to benchmark other organic semiconductors. ${ }^{[2]}$ In addition, the electronic structure of this highly symmetric alternant hydrocarbon can be well-understood by Hückel theory, ${ }^{[3]}$ while also the intermolecular coupling in molecular solids was analyzed theoretically in detail. ${ }^{[4]}$ On the other hand, there are the disadvantages of the larger acenes such as their sensitivity to oxidation and light-induced dimerization of the central ring as well as their low solubility in organic solvents, ${ }^{[5]}$ which complicates their processing in organic electronics. To address these problems, synthetic strategies such as the addition of functional side groups or heterosubstitutions have been developed to enhance the chemical stability and processability. ${ }^{[6,7]}$

A different approach is the substitution of the central ring by chemically more robust moieties such as thienothiophenes, ${ }^{[8]}$ which has led to the synthesis of a new class of diacene-fused thienothiophenes (DAcTT). ${ }^{[9]}$

Among this new material class, the dinaphtothienothiophene (DNTT) 5 stands out because it combines superior charge carrier mobility with excellent stability against oxidation and chemical decomposition, making it one of the most stable organic semiconductors. ${ }^{[10-13]}$ Increased solubility has also been realized for DNTTs by addition of peripheral side chains. ${ }^{[14]}$ Adjustments of the electronic structure of such $\pi$-conjugated systems are possible either through modification of their length ${ }^{[15-17]}$ or incorporation of further thiophene moieties. ${ }^{[9,18-20]}$

A different, for polycyclic aromatic hydrocarbons well-established, strategy is heteroatom substitution, which allows precise tailoring of the molecular properties. ${ }^{[5,21-23]}$ In particular fluorination has become a common strategy to alter the electronic properties of organic semiconductors, ${ }^{[24]}$ as the polar C-F bonds directly lower the energy levels of the $\pi$-system and simultaneously change the charge density distribution leading to electron accumulation at the fluorine atoms. ${ }^{[25-30]}$ Partially fluorinated pentacenes 2 and azapentacenes 3 have been studied. ${ }^{[29,30]}$ So far, however, fluorination has rarely been used to functionalize the vast class of thienoacene-based organic semiconductors with $\mathbf{4}$ as rare example. ${ }^{[31]}$ Here, we introduce partially fluorinated DNTTs 7 and 8.
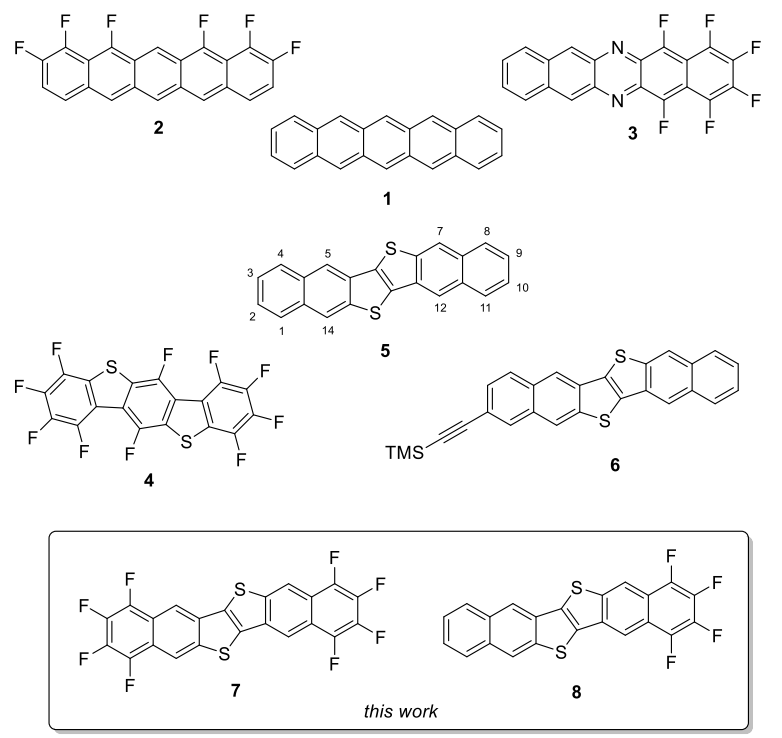

Figure 1. Examples for functionalized pentacenes, benzobisbenzothiophenes and DNTTs.

We present new synthetic strategies to chemically alter the electronic properties of the more promising semiconductor DNTT by partial fluorination. For the symmetrically fluorinated $F_{8}$ DNTT (7) we utilized a McMurry approach, while for the one-sidedly fluorinated $\mathrm{F}_{4} \mathrm{DNTT}$ (8) we had to apply a Wittig approach. Using 
DFT-based electronic structure calculations, X-ray absorption spectroscopy (NEXAFS) and UV/Vis measurements we observe a similar reduction of the HOMO and LUMO levels, leaving the optical gap virtually unchanged. We also observe a reduced exciton binding energy in thin films. Last, we have analyzed the electronic structure of the DNTTs more in detail, revealing that the building block principle can be applied for DNTTs as well.

Retrosynthetic pathways towards functionalized DNTTs of type 9 are shown in scheme 1. The group of Takimiya developed different synthetic methods for symmetric as well as nonsymmetric DNTTs. ${ }^{[10,14,32-35]}$ For symmetric compounds, an olefinic precursor 10 is used, which can undergo an iodinepromoted double-ring-closing reaction to the corresponding DNTT 9. In previous studies of Takimiya, the olefinic precursor 10 is build up in an ortho-thiomethylation/McMurry-sequence starting from aldehyde 11. ${ }^{[10]}$ While the McMurry-reaction of these compounds usually works smoothly, the ortho-thiomethylation of aldehyde $\mathbf{1 1}$ is very tedious, due to the formation of a regioisomer and difficult chromatographic isolation. In 2011, they reported a different strategy for the synthesis of the olefinic precursor $\mathbf{1 0}$, utilizing a double Stille-reaction of triflate 12 with the bisstannane $13{ }^{[32]}$ While the Stille-reaction gave good to excellent yield, this route also has the advantage, that the introduction of the thiomethyl moiety works with a high selectivity in the desired 3-position.

A different strategy had to be developed for the selective synthesis of non-symmetric functionalized DNTT-derivatives. A possible pathway for this problem was shown by Takimiya when the final step of the synthesis is a thio-Friedel-Crafts-type ringclosure of the sulfoxide-precursor 14. ${ }^{[33]}$ This precursor can be synthesized via a Stille-coupling of the functionalized naphthothiophene 16 with triflate 15, allowing the introduction of a non-symmetric substitution pattern. Takimiya showed the applicability of this route by the selective synthesis of 2-bromoDNTT, which was derivatized in a late-stage functionalization into different non-symmetric DNTTs, including the TMS-acetylenecompound 6. ${ }^{[33]}$

In this contribution we demonstrate the synthesis of partially fluorinated DNTTs 7 and 8 . In the case of the symmetric $\mathrm{F}_{8} \mathrm{DNTT}$ (7), we applied the McMURRY-approach to build up the olefinic precursor 10. The aldehyde $\mathbf{1 7}$ is, however, synthesized in a highly regioselective ortho-borylation/deborothiomethylationsequence of ester 18, based on a work by Hosoya. ${ }^{[36]}$ For the synthesis of the non-symmetric $\mathrm{F}_{4} \mathrm{DNTT}(\mathbf{8})$, a new route was developed, including the synthesis of the olefinic precursor $\mathbf{1 0}$ in a Wittig-reaction. The advantage of this route is, that the phosphoniumbromide 19 can also be synthesized utilizing the same strategy, starting from an ester of type $\mathbf{1 8 .}$

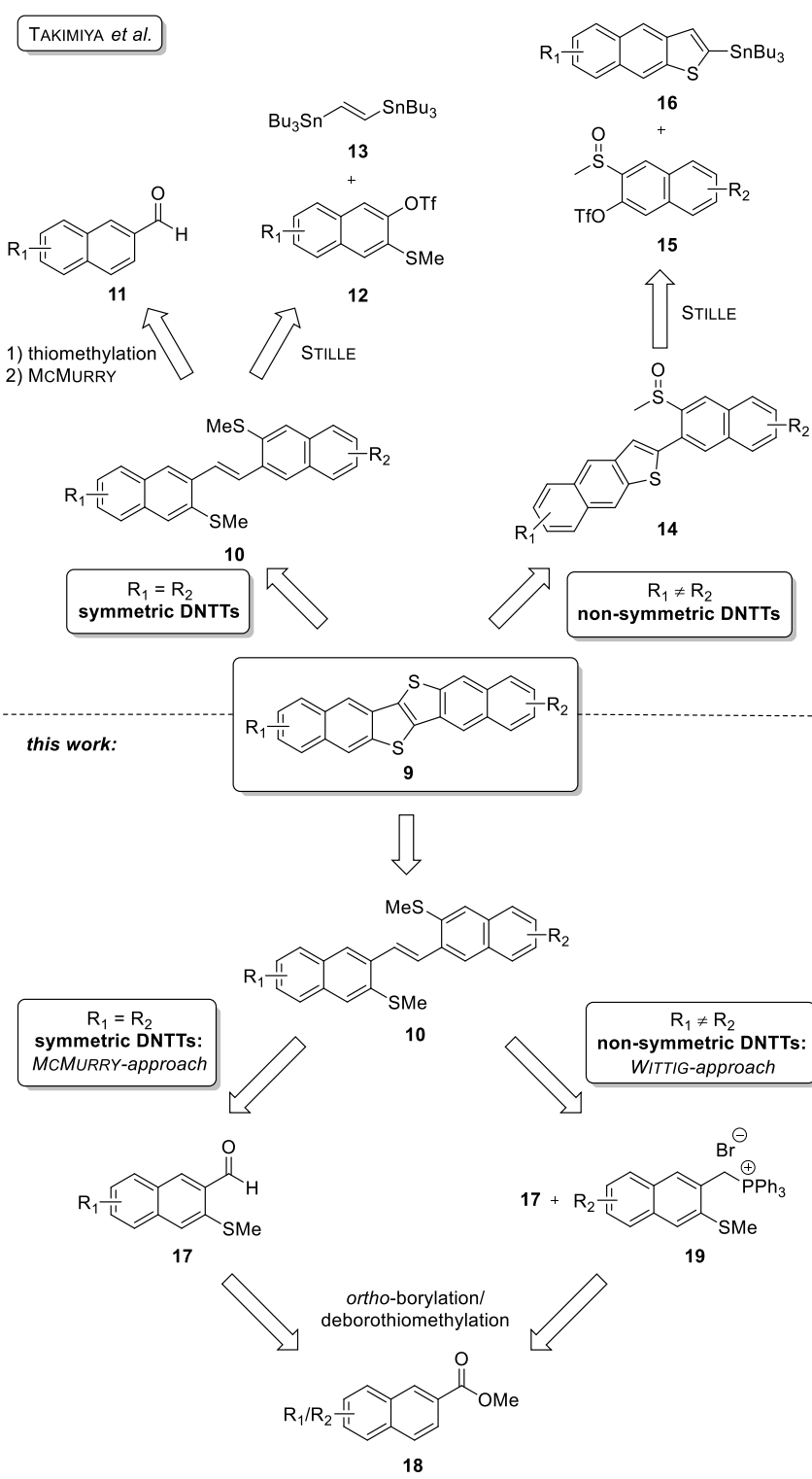

Scheme 1. Retrosynthesis of functionalized DNTTs.

\section{Results and Discussion}

Starting point of the syntheses was the known tetrafluoronaphthyltriflate $\mathbf{2 0},{ }^{[37]}$ that was converted to aldehyde 23 in five steps, which served as a common precursor for both partially fluorinated DNTTs (scheme 2). The first step was a carbonylative cross coupling ${ }^{[38]}$ of $\mathbf{2 0}$ to methyl ester $\mathbf{2 1}$, followed by an iridium catalyzed directed ortho-borylation. ${ }^{[39]}$ The crude pinacolboronate was subjected to a deborothiomethylationprocedure $^{[36]}$ to provide thioether 22 in excellent yield and regioselectivity over two steps. Reduction of the ester to the alcohol using DIBAH and reoxidation under Swern-conditions gave aldehyde 23 . 
<smiles>CCOc1ccc2c(F)c(F)c(F)c(F)c2c1</smiles>

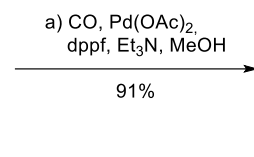<smiles>COC(=O)c1ccc2c(F)c(F)c(F)c(F)c2c1</smiles>

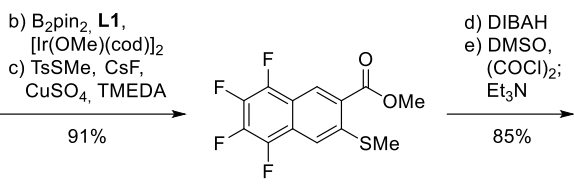

22

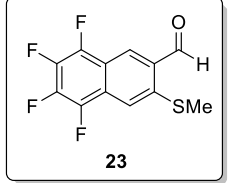

Scheme 2. Synthesis of aldehyde 23. Reagents and conditions: a) CO (1 atm), $\mathrm{Pd}(\mathrm{OAc})_{2}$ (5 mol\%), dppf (10 mol\%), $\mathrm{Et}_{3} \mathrm{~N}(2.0 \mathrm{eq}), \mathrm{DMF} / \mathrm{MeOH}, 65^{\circ} \mathrm{C}, 6 \mathrm{~h}$; b) $[\operatorname{Ir}(\mathrm{OMe})(\mathrm{cod})]_{2}(2.5 \mathrm{~mol} \%), \mathrm{L1}(5 \mathrm{~mol} \%), \mathrm{B}_{2} \mathrm{pin}_{2}(1.0 \mathrm{eq}), \mathrm{THF}, 55^{\circ} \mathrm{C}, 2 \mathrm{~h}$; c) TsSMe (1.2 eq), CsF (2.0 eq), $\mathrm{CuSO}_{4}(0.1 \mathrm{eq}), \mathrm{TMEDA}(0.12 \mathrm{eq}), \mathrm{MeOH}$ $50{ }^{\circ} \mathrm{C}, 26 \mathrm{~h}$; d) DIBAH (3.0 eq), THF, $0{ }^{\circ} \mathrm{C}$ to rt, $20 \mathrm{~min}$; e) $(\mathrm{COCl})_{2}(1.5 \mathrm{eq})$, DMSO (3.0 eq), $\mathrm{CH}_{2} \mathrm{Cl}_{2},-78^{\circ} \mathrm{C}, 30 \mathrm{~min} ; \mathrm{Et}_{3} \mathrm{~N}$ (5.0 eq), $-78^{\circ} \mathrm{C}, 30 \mathrm{~min} ; \mathrm{rt}, 15 \mathrm{~min}$

Since the $\mathrm{F}_{8} \mathrm{DNTT}(\mathbf{7})$ is a symmetric compound, the carbonbackbone can be built up in a McMurry-reaction of aldehyde $\mathbf{2 3}$ (scheme 3). The reaction worked smoothly in $93 \%$ yield to obtain the olefinic precursor 24. Unfortunately, the final double-ringclosing reaction, using an excess of iodine in boiling dichloroethane or acetic acid, did not give the desired DNTT. The main product of the reaction was compound 25 , where only one of the thiophene rings was closed, with the other thiomethyl-group still intact. The thiomethyl-group was then oxidized to the corresponding sulfoxide $\mathbf{2 6}$ using $m \mathrm{CPBA}$ and cyclized in a thioFridel-Crafts type reaction ${ }^{[33]}$ to obtain $\mathrm{F}_{8}$ DNTT (7).
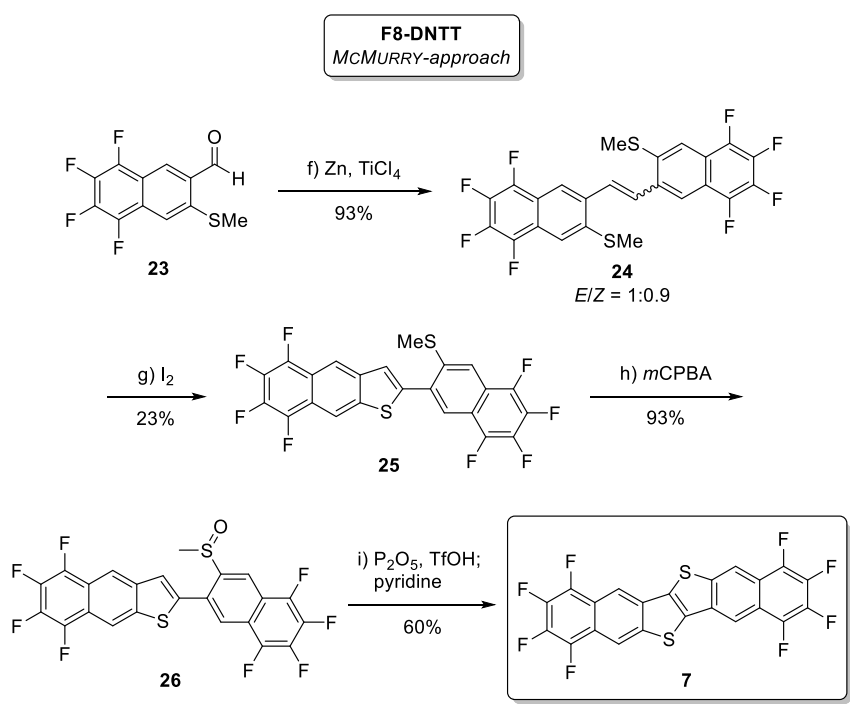

Scheme 3. Synthesis of $\mathrm{F}_{8}$ DNTT 7. Reagents and conditions: f) $\mathrm{TiCl}_{4}(3.0 \mathrm{eq})$, $\mathrm{Zn}(3.0 \mathrm{eq}), \mathrm{THF}, 0^{\circ} \mathrm{C}$ to $66^{\circ} \mathrm{C}, 3 \mathrm{~h} ; 23(1.0 \mathrm{eq})$, rt to $\left.66^{\circ} \mathrm{C}, 14 \mathrm{~h} ; \mathrm{g}\right) \mathrm{I}_{2}(29.0 \mathrm{eq})$, $\left(\mathrm{CH}_{2} \mathrm{Cl}\right)_{2}, 84{ }^{\circ} \mathrm{C}, 22 \mathrm{~h}$; h) $m$ CPBA $(1.0 \mathrm{eq}), \mathrm{CH}_{2} \mathrm{Cl}_{2}, 0{ }^{\circ} \mathrm{C}$ to rt, $26 \mathrm{~h}$; i) $\mathrm{P}_{2} \mathrm{O}_{5}$ (1.0 eq), TfOH, rt, $3 \mathrm{~d}$; pyridine, $115^{\circ} \mathrm{C}, 23 \mathrm{~h}$.

A different strategy had to be developed for the synthesis of $\mathrm{F}_{4} \mathrm{DNTT}(\mathbf{8})$. The non-symmetric olefinic precursor $\mathbf{3 0}$ could be build up in a Wittig-reaction. The corresponding phosphonium bromide 29 should be accessible in five steps, starting from ester 27, using the same strategy to introduce the thiomethyl group. For this substrate the ortho-borylation/deborothiomethylation sequence to obtain $\mathbf{2 8}$ worked in $67 \%$ yield over two steps, indicating that the ortho-borylation works better for electron-deficient compounds. The ester moiety of $\mathbf{2 8}$ was then reduced to the corresponding alcohol and subjected to an Appelreaction. The benzylic bromide was then refluxed in toluene with $\mathrm{PPh}_{3}$ to obtain phosphonium bromide 29 in $70 \%$ yield over 3 steps. The following Wittig-reaction with aldehyde 23 worked smoothly, to give alkene $\mathbf{3 0}$ in $96 \%$ yield. This time, the iodine-promoted cyclization to $\mathrm{F}_{4} \mathrm{DNTT}(\mathbf{8})$ worked fine in one step with $73 \%$ yield (see scheme 4).
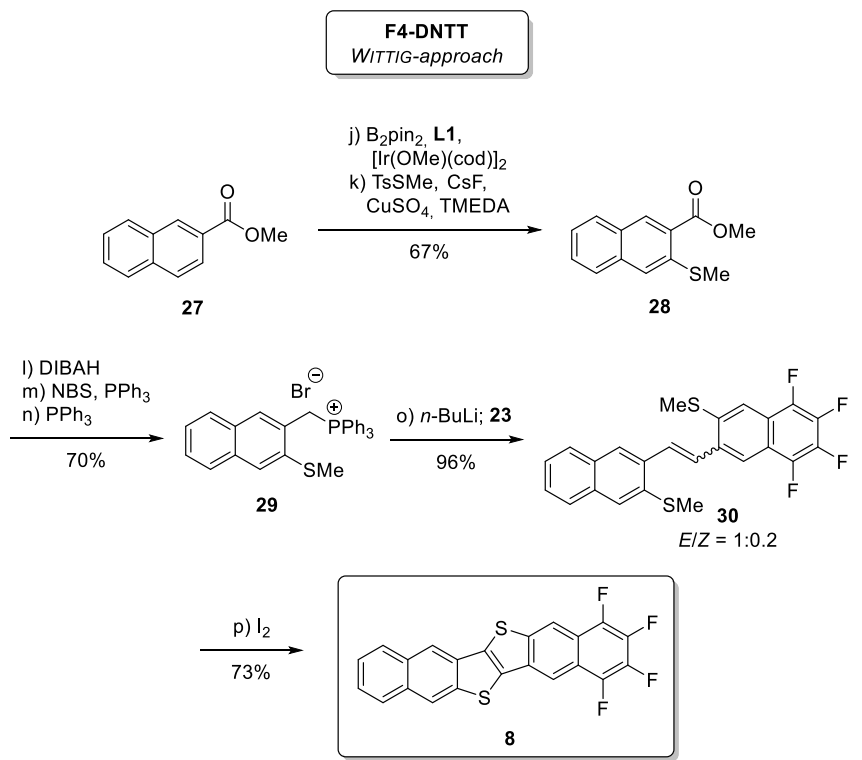

Scheme 4. Synthesis of $F_{4} D N T T$ 8. Reagents and conditions: j) [Ir(OMe)(cod)] (2.5 mol\%), L1 (5 mol\%), B2pin (1.0 eq), THF, $55^{\circ} \mathrm{C}, 22 \mathrm{~h}$; k) TsSMe (1.2 eq), $\mathrm{CsF}$ (2.0 eq), $\mathrm{CuSO}_{4}(0.1 \mathrm{eq}), \mathrm{TMEDA}(0.12 \mathrm{eq}), \mathrm{MeOH}, 50^{\circ} \mathrm{C}, 22 \mathrm{~h}$; I) DIBAH (3.0 eq), THF, $0^{\circ} \mathrm{C}$ to rt, $2 \mathrm{~h}$; m) NBS (2.0 eq), $\mathrm{PPh}_{3}(2.0 \mathrm{eq}), \mathrm{CH}_{2} \mathrm{Cl}_{2}, 0^{\circ} \mathrm{C}, 1 \mathrm{~h}$; n) $\mathrm{PPh}_{3}(1.2 \mathrm{eq})$, toluene, $110^{\circ} \mathrm{C}, 17 \mathrm{~h}$; o) 29 (1.1 eq), $n$-BuLi (1.09 eq), THF, $0^{\circ} \mathrm{C}, 30 \mathrm{~min} ; 23$ (1.0 eq), $0^{\circ} \mathrm{C}$ to rt, $\left.15 \mathrm{~min} ; \mathrm{p}\right) \mathrm{I}_{2}(29.0 \mathrm{eq}), \mathrm{AcOH}, 118^{\circ} \mathrm{C}, 21 \mathrm{~h}$.

In addition to the chemical synthesis also the opto-electronic properties of the new compounds were analysed and compared to the unsubstituted DNTT (5). At first we studied the influence of partial fluorination on the electronic structure by means of DFT calculations. The results are visualized in figure 2. As expected, the fluorine atoms prove to be strongly electron-withdrawing, which affects the charge density distribution within the molecule. In the case of DNTT (5) a high electrostatic potential (indicated by blue color) is present at the molecular rim and a low electrostatic potential (indicated by red color) and thus a high electron density appears in the center, while for the fluorinated species also the outer fluorine atoms exhibit a high electron density, yielding a nearly inverted electrostatic potential at the fluorinated aromatic subunits. For $\mathrm{F}_{4} \mathrm{DNTT}(\mathbf{8})$ the asymmetric functionalization even leads to a permanent molecular dipole moment of $|\mathbf{p}|=4.26 \mathrm{D}$, which is slightly smaller than the dipole moment of related fluoroazaacenes (tetrafluorodiazatetracene: $|\mathbf{p}|=4.31 \mathrm{D}$, hexafluorodiazapentacene 3: $|\mathbf{p}|=5.27$ D). ${ }^{[29]}$ The electron withdrawing effect of the fluorine atoms leads to a reduction of the electron 
density at the carbon atoms which not only affects the electrostatic potential through the frontier orbitals but also increases the $\mathrm{C} 1 \mathrm{~s}$ binding energy upon fluorination, which transfers in the sense of Hückel theory to a larger Coulomb integral. ${ }^{[3]}$ This leads to a lowering of the energy levels of the $\pi$ system, including the frontier orbitals HOMO and LUMO. Interestingly, in the case of the partially fluorinated DNTTs, the energy levels of both frontier orbitals are lowered almost equally, so that the optical gap changes only marginally. According to Hückel theory, this effect is expected for alternant hydrocarbons [25] and has been verified experimentally for other fluorinated organic semiconductors such as e.g. acenes, rubrene and hexabenzocoronene. ${ }^{[26-30]}$ The presently observed effect of an (approximately) equal energetically reduction of both frontier orbitals due to fluorination, even in the case of non-alternating hydrocarbons such as DNTT, suggests that partial fluorination generally leads to a reduction in both frontier orbitals for $\pi$ conjugated molecules.

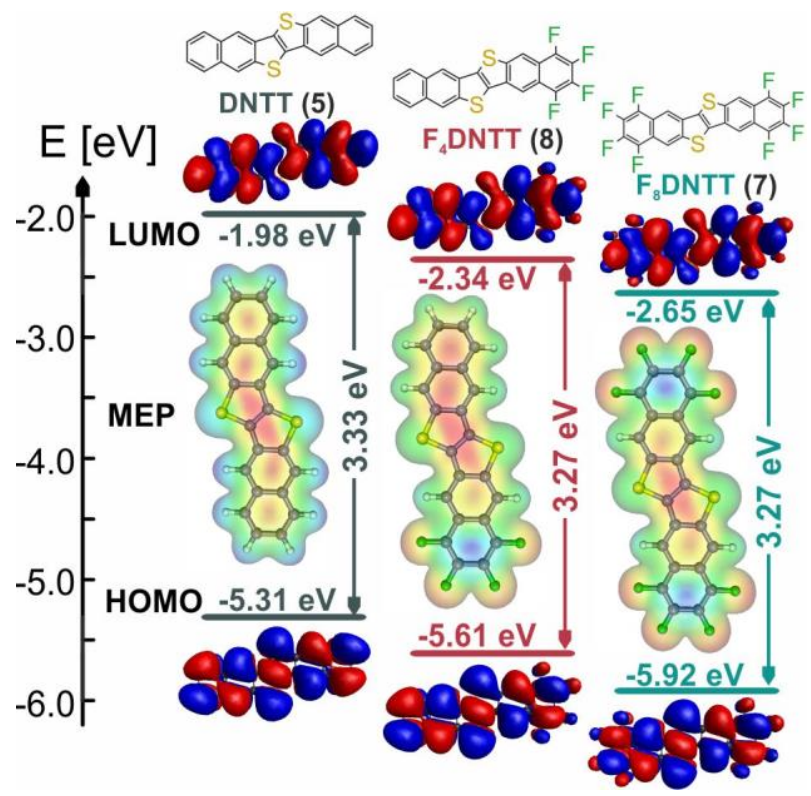

Figure 2. Comparison of calculated energy levels, frontier orbitals $\mathrm{HOMO}$ and LUMO and molecular electrostatic potentials (MEPs) of DNTT (5), F4DNTT (8) and $F_{8}$ DNTT (7) obtained with GAMESS-US at the B3LYP/6-311G(d,p) level.

The molecular HOMO-LUMO gap was experimentally obtained by optical spectroscopy. UV/Vis solution spectra (cf. figure 3) yield HOMO-LUMO gaps of $3.09 \mathrm{eV}$ (DNTT (5)), $3.04 \mathrm{eV}\left(\mathrm{F}_{4} \mathrm{DNTT}(\mathbf{8})\right)$ and $3.03 \mathrm{eV}\left(\mathrm{F}_{8} \mathrm{DNTT}(\mathbf{7})\right)$, respectively. Hence the experimental data show only a slight reduction of the HOMO-LUMO gap and are qualitatively consistent with the DFT calculations. Since for device applications the optical solid-state properties are more relevant, we also carried out UV/Vis absorption measurements on solid molecular thin films of about $50 \mathrm{~nm}$ evaporated under vacuum conditions onto quartz slides. As depicted in figure 3 , the transmission absorption spectra exhibit new bands below the HOMO-LUMO transition, which can be assigned to excitonic transitions in the solid. The exciton binding energies, which can be approximated by the difference between the lowest energy excitation in solution and in the solid (indicated as $\Delta E$ in figure 3 ), are notably smaller for the partially fluorinated molecules, when compared to the non-fluorinated pendent DNTT (5) (DNTT: $330 \mathrm{meV} \mathrm{F}_{4} \mathrm{DNTT}$ (8): $180 \mathrm{meV}, \mathrm{F}_{8} \mathrm{DNTT}$ (7): $160 \mathrm{meV}$ ). Hence the optical solid state properties are modified notably upon fluorination, as also observed for partially fluorinated acenes, which could be attributed to a changed packing motif in the respective molecular solids. ${ }^{[30,40]}$ Unfortunately, a crystal structure analysis that would rationalize this effect has not yet been possible, because the crystallites obtained so far are too small. This is in line with our observation that fluorinated aromatic molecules generally tend to crystallize in smaller crystallites than their non-fluorinated pendants. ${ }^{[30]}$

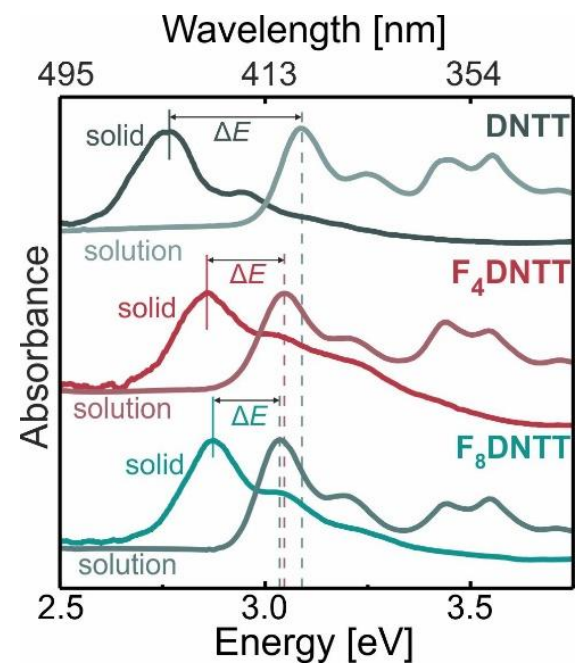

Figure 3. UV/Vis spectra of DNTT (5), $\mathrm{F}_{4} \mathrm{DNTT}(\mathbf{8})$ and $\mathrm{F}_{8} \mathrm{DNTT}(\mathbf{7})$ in solution (saturated solution in $\mathrm{CH}_{2} \mathrm{Cl}_{2}$ ) and as solid films evaporated onto quartz glass substrates. The dashed lines indicate the energy of the lowest absorption band (optical gap). Arrows visualize the exciton binding energies $(\Delta E)$.

To obtain deeper insights into the nature of unoccupied electronic states, we have utilized NEXAFS spectroscopy. The carbon Kedge NEXAFS spectrum of $F_{4}$ DNTT (8) (cf. figure 4a) exhibits sharp $\pi^{*}$-resonances, which can be assigned to excitations from $\mathrm{C} 1 \mathrm{~s}$ core levels into unoccupied molecular $\pi$-orbitals, and broad resonances corresponding to excitations in unoccupied $\sigma$-orbitals. The comparison of the magnified $\pi^{*}$ region of the differently fluorinated DNTTs (cf. figure $4 \mathrm{~b}$ ) shows that some resonances appear at unchanged positions, while others occur only for the fluorinated species. This is particular pronounced for $\mathrm{F}_{4} \mathrm{DNTT}$ (8) which exhibits final states with mixed character, as it has also been observed also for unilaterally fluorinated acenes. ${ }^{[30]}$ As DNTT topologically consists of naphthalene and thiophene units, a comparison of the corresponding signatures is useful. Indeed, the NEXAFS spectrum of DNTT can be well-described by the NEXAFS signatures of these units, ${ }^{[41,42]}$ as indicated by the dashed lines (blue: naphthalene-like resonance, orange: thiophene-like resonance, more details are given in Supp. Inf.). In addition, the carbon K-edge NEXAFS spectrum of $F_{8}$ DNTT (7) can be well described by the spectra of DNTT and perfluoronaphthalene, since $F_{8}$ DNTT (7) consists of thiophene units and semifluorinated naphthalene units, which impressively shows that the building block principle can be used to understand complex 
NEXAFS spectra. We note that the comparison of $\mathrm{F}_{8} \mathrm{DNTT}(\mathbf{7})$ with perfluorobenzene would not be sufficient, as the resonance at $286.4 \mathrm{eV}$ results from carbon atoms not directly bond to fluorine atoms (indicated by purple line). ${ }^{[43]}$ More details on the building blocks of DNTT as well as a topological justification of the high chemical stability and low lying HOMO of DNTT-derivatives based on Hückel theory are presented in the supporting information.

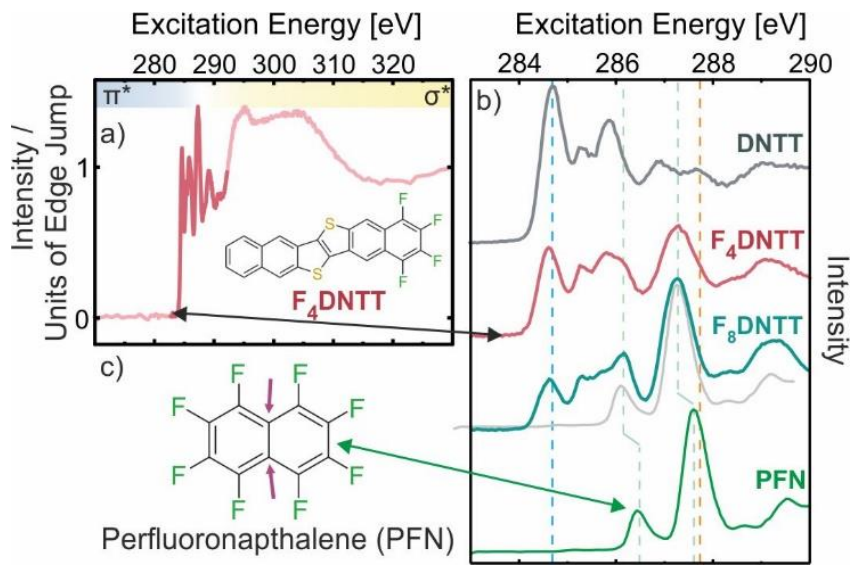

Figure 4. Summary of carbon K-edge NEXAFS data of the differently fluorinated DNTTs obtained for their solid films grown on $\mathrm{SiO}_{2}$ substrates and recorded at an incident angle of $55^{\circ}$. a) NEXAFS spectrum of a thin film of $F_{4}$ DNTT (8) prepared on $\mathrm{SiO}_{2} . \mathrm{b}$ ) Comparison of the leading NEXAFS resonances of $\operatorname{DNTT}(5), \mathrm{F}_{4} \mathrm{DNTT}(8), \mathrm{F}_{8} \mathrm{DNTT}(7)$ and perfluoronaphthalene (PFN, which is shown in C) and taken from ref. [43]). The gray line represents an energetically shifted PFN spectrum, which resembles the features of F8DNTT at energies larger than $286 \mathrm{eV}$ surprisingly well.

\section{Conclusion}

In conclusion, the syntheses of two partially fluorinated DNTTs 1,2,3,4-tetrafluoro-dinaphtothienothiophene ( $\mathrm{F}_{4} \mathrm{DNTT}(\mathbf{8})$ and 1,2,3,4,8,9,10,11-octafluoro-dinaphtothienothiophene ( $F_{8}$ DNTT (7)) were accomplished via McMurry coupling or Wittig olefination of partially fluorinated naphthalene precursors and subsequent formation of the thienothiophene core. The electron withdrawing character of the fluorine atoms strongly modifies the charge distribution and leads to a likewise reduction of both frontier orbital energy levels, thus only slightly reducing the optical band gap. As DNTTs are non-alternant $\pi$-conjugated molecules, this appears to be a general effect of fluorination. Furthermore the carbon $\mathrm{K}$ edge NEXAFS spectra of these compounds can roughly be built up from their building blocks naphthalene, thiophene and perfluoronaphthalene, examining that the building block principle can be used to shed a light on the electronic structure of such extended $\pi$-conjugated systems. The high chemical stability of the (partially fluorinated) DNTTs can be attributed to the low lying HOMO originating from the topological structure of these molecules.

\section{Acknowledgements}

We acknowledge support by the German Science Foundation (Grant SFB 1083, TP A2 and A8) and thank the Helmholtz Center Berlin (electron storage ring BESSY II) for provision of synchrotron radiation at the beamline HE-SGM. The authors thank Dr. Xiulan Xie for helpful discussions for the measurement and assignment of the NMR spectra.

Keywords: DNTT • electronic structure $•$ fluorination • optical properties $\cdot$ synthesis design

[1] J.-L. Brédas, S. R. Marder in The WSPC reference on organic electronics: Organic Semiconductors, Vols. 1 and 2, World Scientific, 14 2016.

[2] T. W. Kelley, L. D. Boardman, T. D. Dunbar, D. V. Muyres, M. J. Pellerite T. P. Smith, J. Phys. Chem. B 2003, 107, 5877-5881.

[3] M. Klessinger, Elektronenstruktur Organischer Moleküle, Verlag Chemie, Weinheim, 1982, Bd. 1.

[4] J. Cornil, J. P. Calbert, L. Brédas, J. Am. Chem. Soc. 2001, 123, 12501251.

[5] J. E. Anthony, Angew. Chem. Int. Ed. 2008, 47, 452-283.

[6] J. E. Anthony, J. S. Brooks, D. L. Eaton, S. R. Parkin, J. Am. Chem. Soc. 2001, 123, 9482-9483.

[7] A. Maliakal, K. Raghavachari, H. Katz, E. Chandross, T. Siegrist, Chem Mater. 2004, 16, 4980-4986.

[8] M. E. Cinar, T. Ozturk, Chem. Rev. 2015, 115, 3036-3140.

[9] K. Takimiya, S. Shinamura, I. Osaka, E. Miyazaki, Adv. Mater. 2011, 23, 4347-4370.

[10] T. Yamamoto, K. Takimiya, J. Am. Chem. Soc. 2007, 129, 2224-2225.

[11] U. Zschieschang, F. Ante, T. Yamamoto, K. Takimiya, H. Kuwabara, M. Ikeda, T. Sekitani, T. Someya, K. Kern, H. Klauk, Adv. Mater. 2010, 22, 982-985.

[12] U. Zschieschang, F. Ante, D. Kälblein, T. Yamamoto, K. Takimiya, H. Kuwabara, M. Ikeda, T. Sekitani, T. Someya, J. Blockwitz-Nimoth, H. Klauk, Org. Electron. 2011, 12, 1370-1375.

[13] M. Kaltenbrunner, T. Sekitani, J. Reeder, T. Yokota, K. Kuribara, T. Tokuhara, M. Drack, R. Schwödiauer, I. Graz, S. Bauer-Gogonea, S Bauer and T. Someya, Nature 2013, 499, 458-463.

[14] H. Ebata, T. Izawa, E. Miyazaki, K. Takimiya, M. Ikeda, H. Kuwabara, T. Yui, J. Am. Chem. Soc. 2007, 129, 15732-15733.

[15] K. Niimi, S. Shinamura, I. Osaka, E. Miyazaki, K. Takimiya, J. Am. Chem. Soc. 2011, 133, 8732-8739.

[16] T. Mori, T. Nishimura, T. Yamamoto, I. Doi, E. Miyazaki, I. Osaka, K. Takimiya, J. Am. Chem. Soc. 2013, 135, 13900-13913.

[17] S. Vásquez-Céspedes, A. Ferry, L. Candish, F. Glorius, Angew. Chem. Int. Ed. 2015, 54, 5772-5776.

[18] K. Takimiya, I. Osaka, T. Mori, M. Nakano, Acc. Chem. Res. 2014, 47, 1493-1502

[19] J.-I. Park, J. W. Chung, J.-Y. Kim J. Lee, J. Y. Jung, B. Koo, B.-L. Lee, Y. W. Jin, S. Y. Lee, J. Am. Chem. Soc. 2015, 137, 12175-12178.

[20] T. Zheng, Z. Cai, R. Ho-Wu, S. H. Yau, V. Shaparov, T. Goodson, III, L. Yu, J. Am. Chem. Soc. 2016, 138, 868-875

[21] U. H. F. Bunz, J. Freudenberg, Acc. Chem. Res. 2019, 52, 1575-1587.

[22] M. Krieg, F. Reicherter, P. Haiss, M. Ströbele, K. Eichele, M.-J. Treanor R. Schaub, H. F. Bettinger, Angew. Chem. Int. Ed. 2015, 54, 8284-8286.

[23] M. Klues, G. Witte, CrystEngComm 2018, 20, 63-74.

[24] M. L. Tang, Z. Bao, Chem. Mater. 2011, 23, 446-455.

[25] B. M. Medina, D. Beljonne, H.-J. Egelhaaf, J. Gierschner, J. Chem. Phys. 2007, 126, 111101.

[26] F. Anger, T. Breuer, A. Ruff, M. Klues, A. Gerlach, R. Scholz, S. Ludwigs, G. Witte, F. Schreiber, J. Phys. Chem. C 2016, 120, 5515-5522.

[27] T. Breuer, M. Klues, P. Liesfeld, P. Viertel, M. Conrad, S. Hecht, G. Witte, Phys. Chem. Chem. Phys. 2016, 18, 33344-33350.

[28] T. Geiger, S. Schundelmeier, T. Hummel, M. Ströbele, W. Leis, M. Seitz, C. Zeiser, L. Moretti, M. Maiuri, G. Cerullo, K. Broch, J. Vahland, K. Leo, 
C. Maichle-Mössmer, B. Speiser, H. F. Bettinger, Chem. Eur. J. 2020, 26, 3420-3434.

[29] J. Schwaben, N. Münster, M. Klues, T. Breuer, P. Hofmann, K. Harms, G. Witte, U. Koert, Chem. Eur. J. 2015, 21, 13758-13771.

[30] P. E. Hofmann, M. W. Tripp, D. Bischof, Y. Grell, A. L. C. Schiller, T. Breuer, S. I. Ivlev, G. Witte, U. Koert, Angew. Chem. Int. Ed. 2020, 59 16501-16505.

[31] Y. Wang, S. R. Parkin, J. Gierschner, M. D. Watson, Org. Lett. 2008, 10, 3307-3310.

[32] K. Niimi, M. J. Kang, E. Miyazaki, I. Osaka, K. Takimiya, Org. Lett. 2011 13, 3430-3433.

[33] K. Kawabata, S. Usui, K. Takimiya, J. Org. Chem. 2020, 85, 195-206.

[34] M. Sawamoto, M. J. Kang, E. Miyazaki, H. Sugino, I. Osaka, K. Takimiya, ACS Appl. Mater. Interfaces 2016, 8, 3810-3824.

[35] M. J. Kang, I. Doi, H. Mori, E. Miyazaki, K. Takimiya, M. Ikeda, H. Kuwabara, Adv. Mater. 2011, 23, 1222-1225.

[36] K. Kanemoto, S. Yoshida, T. Hosoya, Chem. Lett. 2018, 47, 85-88.

[37] J. Mohr, M. Durmaz, E. Irran, M. Oestreich, Organometallics 2014, 33, 1108-1111.

[38] R. E. Dolle, S. J. Schmidt, L. I. Kruse, J. Chem. Soc. Chem. Commun. 1987, 904-905.

[39] B. Ghaffari, S. M. Preshlock, D. L. Plattner, R. J. Staples, P. E. Maligres, S. W. Krska, R. E. Maleczka, M. R. Smith, J. Am. Chem. Soc. 2014, 136 14345-14348.

[40] C. Cocchi, T. Breuer, G. Witte, C. Draxl, Phys. Chem. Chem. Phys. 2018 20, 29724-29736.

[41] G. Tzvetkov, N. Schmidt, T. Strunskus, Ch. Wöll, R. Fink, Surf. Sci. 2007, 601, 2089-2094.

[42] P. Väterlein, M. Schmelzer, J. Taborski, T. Krause, F. Viczian, M. Bäßler R. Fink, E. Umbach, W. Wurth, Surf. Sci. 2000, 452, 20-32.

[43] M. Klues, P. Jerabek, T. Breuer, M. Oehzelt, K. Hermann, R. Berger, G. Witte, J. Phys. Chem. C 2016, 120, 12693-12705. 


\section{Entry for the Table of Contents}

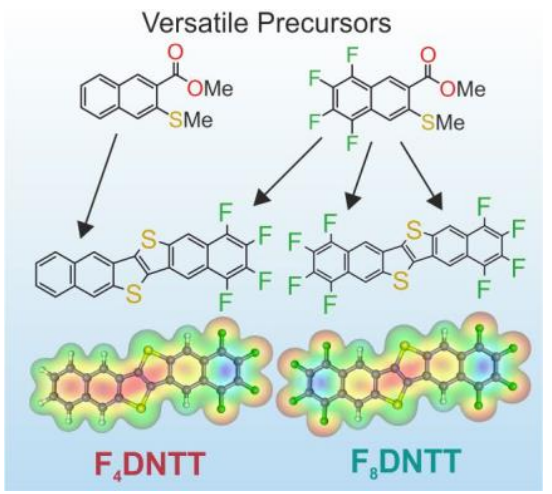

Partially fluorinated dinaphtothienothiophenes (DNTTs) were synthesized via bisthiomethyl alkene intermediates which were accessible by McMurry coupling or Wittig olefination of partially fluorinated naphthalene precursors. The electronic structure of the DNTTs is compared with thiophene and fluorinated naphthalene units. 